\title{
Unusual Oxidation of an N-heterocycle Ligand in Metal-organic
}

\section{Framework}

\author{
Zhangang Han, ${ }^{a, b}$ Jun Peng, ${ }^{* a}$ Yulong Zhao ${ }^{a}$ and Carlos J. Gómez-García ${ }^{c}$
}

${ }^{a}$ Key Laboratory of Polyoxometalate Science of Ministry of Education Institute of Polyoxometalate Chemistry, Department of Chemistry, Northeast Normal University, Changchun, Jilin, 130024, China.

${ }^{b}$ College of Chemistry \& Material Science, Hebei Normal University, Shijiazhuang, Hebei, 050016, China.

${ }^{c}$ Instituto de Ciencia Molecular, Universidad de Valencia, Pol. La Coma, 46980 Paterna, Valencia, Spain

E-mail: hanzg116@yahoo.com.cn

Supporting Materials:

A mixture solution of $\mathrm{Cu}\left(\mathrm{NO}_{3}\right)_{2}(248.7 \mathrm{mg}, 1.0 \mathrm{mmol}), \mathrm{Na}_{2} \mathrm{MoO}_{4}(488.9 \mathrm{mg}, 2.1$ mmol) and bppy(124.0 mg, $0.4 \mathrm{mmol})$ was adjusted to $c a$. $\mathrm{pH} 4.60$ with dilute $\mathrm{H}_{3} \mathrm{PO}_{4}$ solution. The resultant mixture was sealed in a $25 \mathrm{~mL}$ Teflon-lined autoclave $(70 \%$ full) and heated at $170{ }^{\circ} \mathrm{C}$ for $96 \mathrm{~h}$. The autoclave was then cooled at $10{ }^{\circ} \mathrm{C}$ per hour to RT. Blue crystals of 1 were obtained (yield: $79.1 \mathrm{mg}, 63 \%$ based on bppy) along with a few yellow crystals which was characterized as salts of Keggin type polyoxometalate (see S-Fig. 3). The blue crystals were washed with water and dried in a desiccator at ambient temperature. Elemental analysis(\%) calcd for $\mathrm{C}_{24} \mathrm{H}_{14} \mathrm{Br}_{2} \mathrm{Cu}_{1} \mathrm{~N}_{2} \mathrm{O}_{4}$ : C 46.66, $\mathrm{H}$ 2.28, $\mathrm{N}$ 4.53; found: $\mathrm{C} 46.32, \mathrm{H}$ 2.37, $\mathrm{N}$ 4.26. $\operatorname{IR}\left(\mathrm{cm}^{-1}\right)($ see S-Fig. 2): $v=1650(\mathrm{~s}), 1600(\mathrm{~m}), 1480(\mathrm{~m}), 1350(\mathrm{~m}), 1260(\mathrm{w}), 1170(\mathrm{w})$, 1040(w), 1010(w), 833(m), 804(m), 694(w), 501(w) and 444(w). 
S-Fig. 1 A room temperature ${ }^{1} \mathrm{H}$ NMR spectrum of bppy in $\mathrm{CDCl}_{3}$, tetramethylsilane (TMS) was used as an internal reference.

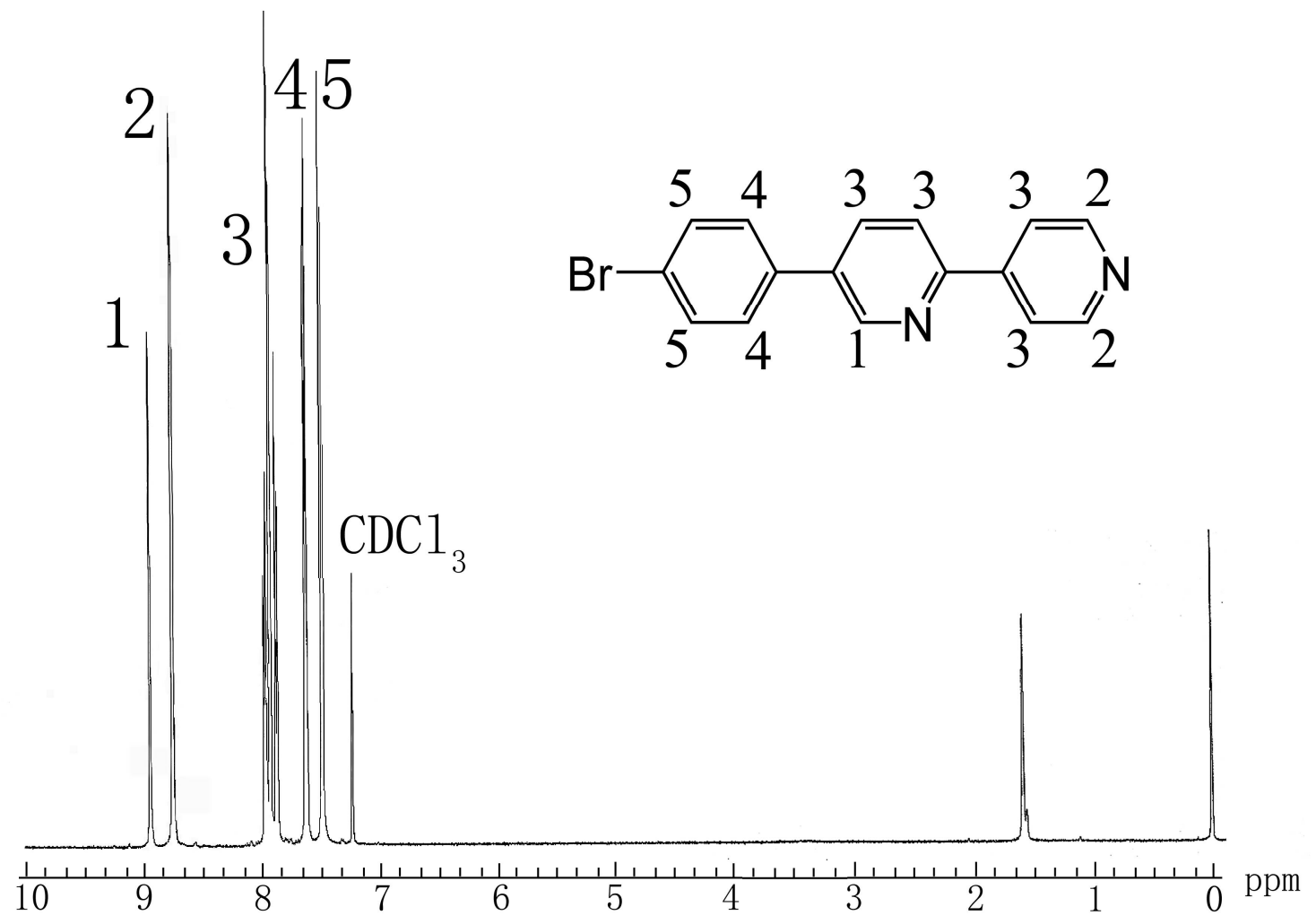

S-Fig. 2 IR spectra of bppy and compound $\mathbf{1 .}$

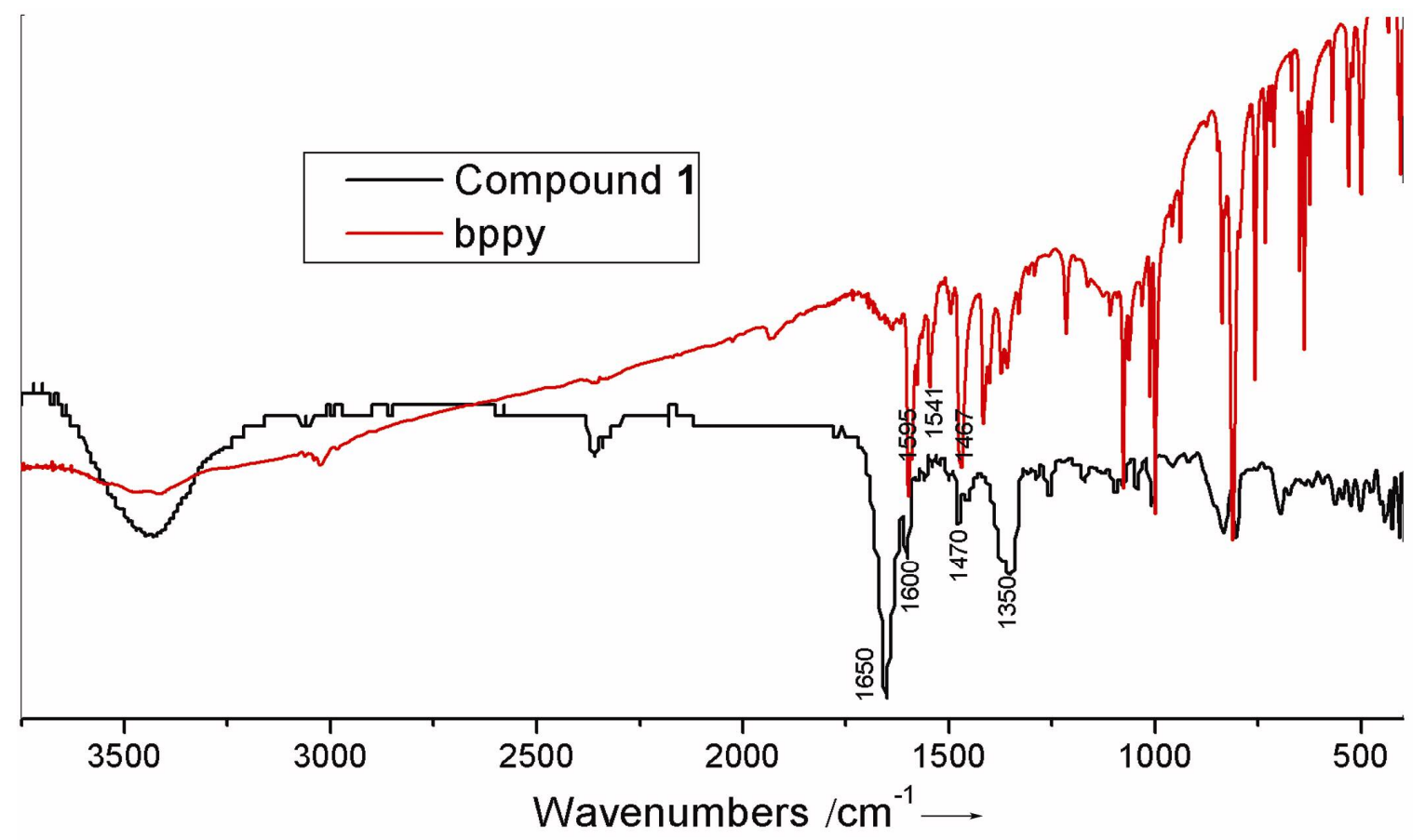


S-Fig. 3 IR spectrum of Keggin type polyoxometalate.

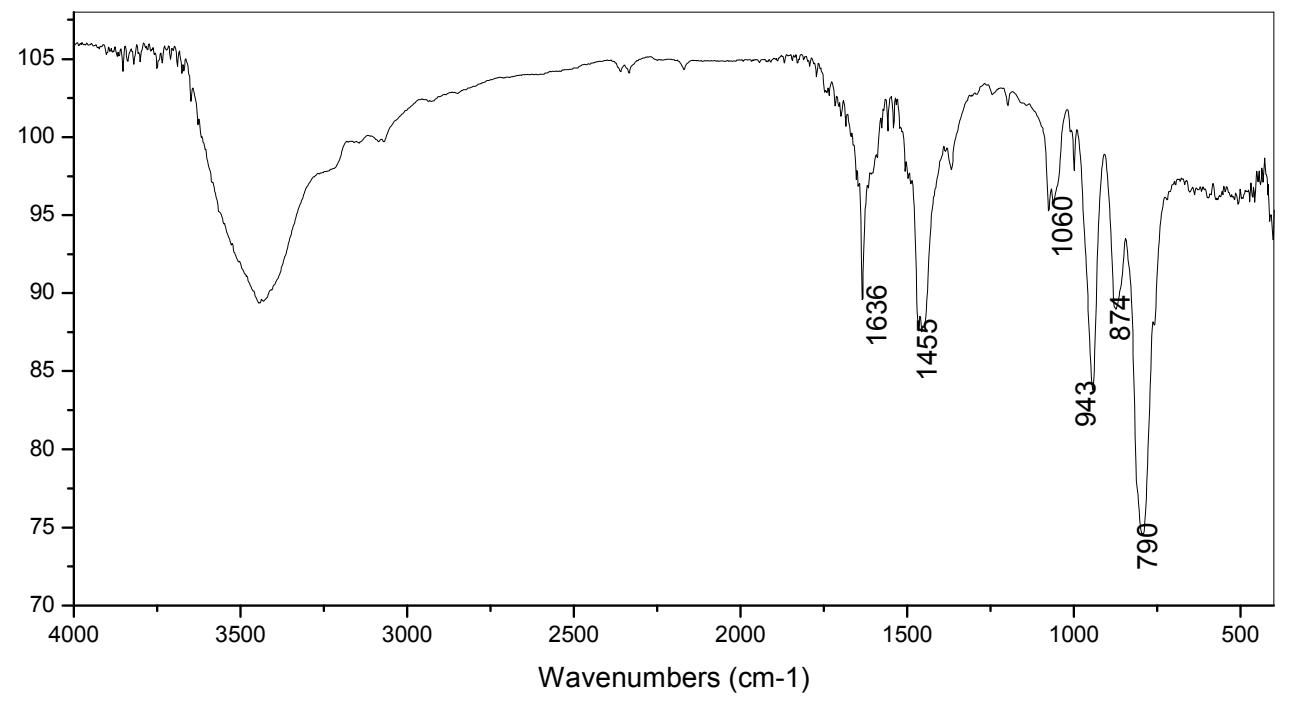

